\title{
Processamento hidrotérmico em escala industrial sobre parâmetros de qualidade em frações de aveia
}

\author{
Hidrothermal processing on an industrial scale on quality parameters in oat fractions
}

\author{
Vera Maria Klajn ${ }^{\mathrm{I}}$ Rosana Colussi ${ }^{\mathrm{II}}$ Ângela Maria Fiorentini ${ }^{\mathrm{II}}$ Moacir Cardoso Elias ${ }^{\mathrm{II}}$ \\ Luiz Carlos Gutkoski ${ }^{\text {II }}$
}

RESUMO

A aveia destaca-se dentre os cereais por seu teor e qualidade proteica, alta porcentagem de lipídios distribuidos por todo o grão e predominância de ácidos graxos insaturados, além de possuir altos teores de fibra alimentar, minerais e antioxidantes, responsáveis pelos efeitos benéficos à saúde humana. Devido aos seus constituintes, a aveia apresenta forte tendência à rancidez $e$, por esse motivo, faz-se necessária a inativação enzimática das cariopses. Na indústria, a inativação normalmente é realizada pelo tratamento hidrotérmico. Objetivou-se, com este trabalho, estudar os efeitos do processamento hidrotérmico em escala industrial sobre parâmetros de composição química, atividade enzimática, $\beta$-glicanas e compostos fenólicos solúveis totais nas frações de aveia farinha, farelo e integral. O processamento industrial da aveia foi realizado em batelada com temperatura e pressão constantes e tempo de retenção na coluna de 37 min e $110 \mathrm{~min}$. O experimento foi conduzido em delineamento inteiramente casualizado, sendo os resultados submetidos à análise de variância e as médias comparadas pelo teste Tukey a 5\% de significância. Os constituintes químicos das frações farinha, farelo e integral foram pouco afetados nos tempos de retenção estudados. O tempo de retenção de 37 min se mostra mais adequado por ser suficiente para inativar as enzimas lipase e peroxidase e preservar os compostos fenólicos solúveis totais em todas as frações de aveia estudadas.

Palavras-chave: Avena sativa, composição química, $\beta$-glicanas, lipase, polifenois.

\section{ABSTRACT}

Oat stands out among other cereals because of its quality as high protein content, high percentage of lipids distributed throughout the grain and predominance of unsaturated fatty acids, in addition oat presents high contents of dietary fiber, minerals and antioxidants responsible for the beneficial effects to human health.
Due to their constituents oats has a strong tendency to rancidity and because of this reason is necessary to enzymatic inactivation of caryopses. In industry, the inactivation is carried out usually by hydrothermal treatment. The objective of this work was to study the effects of hydrothermal processing on an industrial scale. Parameters of chemical composition, enzyme stability, $\beta$-glucan and total soluble phenolic compounds oat fractions (flour, bran and wholemeal) were evaluated. The industrial processing was carried out in batch with constant temperature and pressure and column retention time of $37 \mathrm{~min}$ and $110 \mathrm{~min}$. The experiment was conducted in a completely randomized design and the results were submitted to analysis of variance and means were compared by Tukey test at 5\% significance. The chemical constituents of the fractions flour, bran and whole were little affected the retention times studied. The retention time of $37 \mathrm{~min}$ shown more appropriate for being sufficient to inactivate lipase and peroxidase enzymes and preserve the phenolic total soluble in all oats fractions studied.

Key words: Avena sativa, composition chemistry, $\beta$-glucans, lipase, polyphenols.

\section{INTRODUÇÃO}

Aaveia (Avena sativa L.), cereal pertencente à família Poaceae, destaca-se dentre os demais cereais por sua qualidade e teor proteico, com valores entre $12,4 \%$ e $24,5 \%$ no grão descascado, por sua alta porcentagem de lipídios e distribuídos por todo o grão, com predominância de ácidos graxos insaturados, além de possuir altos conteúdos de fibras alimentares, minerais e antioxidantes responsáveis pelos efeitos benéficos à saúde humana (WEBER et al., 2002).

\footnotetext{
Instituto Federal de Educação, Ciência e Tecnologia Farroupilha (IFFFARROUPILHA), Câmpus Santa Rosa, Rua Uruguai, 1675, 98900-000, Santa Rosa, RS, Brasil. E-mail: veraklajn@gmail.com. Autor para correspondência.

IIDepartamento de Ciência e Tecnologia Agroindustrial (DCTA), Faculdade de Agronomia "Eliseu Maciel" (FAEM), Universidade Federal de Pelotas (UFPEL), Pelotas, RS, Brasil.

IIICentro de Pesquisa em Alimentação (CEPA), Universidade de Passo Fundo (UPF), Passo Fundo, RS, Brasil. Recebido 29.05.13 Aprovado 14.10.13 Devolvido pelo autor 27.02.14 CR-2013-0758.R1
} 
A $\beta$-glicana é uma das frações de fibra alimentar presente na aveia e considerada de grande importância para a saúde humana (WOOD, 2007). O polímero é encontrado em pequenas quantidades em diversos tecidos dos principais cereais e de várias espécies da família Poaceae (BUTT et al., 2008). Essa fibra está localizada nas paredes celulares dos grãos, com maior concentração na subcamada e camada de aleurona e no endosperma amiláceo adjacente ao embrião (CRESTANI et al., 2010).

A aveia apresenta forte tendência à rancidez, devido, principalmente, à presença das enzimas lipases, produtoras de ácidos graxos livres, os quais, por serem de natureza insaturada, são facilmente oxidados a hidroperóxidos, que, em reações posteriores, se transformam em uma grande variedade de compostos de baixo peso molecular (MARINI et al., 2005). A peroxidase é uma enzima excepcionalmente estável ao calor e sua ausência após o tratamento térmico de alimentos frequentemente é utilizada como indicador de que as demais enzimas presentes no produto foram inativadas. $\mathrm{Na}$ indústria, os grãos de aveia são tratados hidrotermicamente por vapor, antes da formação de flocos, a fim de inativar as enzimas hidrolíticas (BUTT et al., 2008). A aveia é reconhecida como fonte de antioxidantes, especialmente compostos fenólicos com atividade comprovada in vitro $e$ sua concentração pode ser afetada por vários fatores como genótipo, tratamento térmico e tipo de produto elaborado (PETERSON, 2001). Com o presente trabalho, objetivou-se estudar os efeitos do processamento hidrotérmico em escala industrial sobre parâmetros de composição química, estabilidade enzimática, teor de $\beta$-glicanas e conteúdo de compostos fenólicos solúveis totais nas frações farinha, farelo e integral de aveia, cultivar URS 21.

\section{MATERIAL E MÉTODOS}

O trabalho foi realizado com emprego de grãos de aveia em casca (Avena sativa L.), cultivar 'URS 21', e os flocos foram produzidos em escala industrial em uma indústria de processamento de aveia da Região Noroeste do Estado do Rio Grande do Sul.

A aveia em casca foi limpa, seca, resfriada, classificada, descascada, polida, cortada entre 3 e 5 pedaços e bateladas de $720 \mathrm{~kg}$, tratadas hidrotermicamente. $\mathrm{O}$ tratador hidrotérmico consiste em uma câmara com altura de $1,5 \mathrm{~m}$, base inferior de $60 \times 45 \mathrm{~cm}$, superior de $50 \times 30 \mathrm{~cm}$, contendo três injetores de vapor para umedecer todas as áreas da coluna durante a queda lenta e gradual das cariopses de grãos cortados e dispõe de um agitador no interior da coluna para uniformizar o processo. $\mathrm{O}$ equipamento contém controladores que monitoram a injeção de vapor, a pressão interna e a temperatura do sistema. O tempo de retenção foi variável, ocorrendo neste período aumento na temperatura das cariopses. Com a injeção de vapor, a umidade das cariopses aumentou de $10 \%$ iniciais para $17 \%$. O equipamento foi regulado em temperatura e pressão de vapor constantes de $110^{\circ} \mathrm{C}$ e $49,05 \mathrm{kPa}$, respectivamente. O tempo de retenção das cariopses na coluna foi de 37 e 110 minutos. As cariopses de aveia foram flocadas e o teor de água reduzido para 7,5\% pelo emprego de secador de leito fluidizado. As amostras de flocos de aveia resultantes de cada processo foram coletadas, identificadas, embaladas e conduzidas ao laboratório de Cereais do Centro de Pesquisa em Alimentação (Cepa) da Universidade de Passo Fundo (UPF).

Os flocos de aveia resultantes de cada tempo de retenção foram moídos em moinho de martelos, marca Trapp, modelo TRF 70 (Brasil), com peneira de $1,18 \mathrm{~mm}$ de abertura e fracionados em aparelho marca Retsch, modelo 1000 (Alemanha), utilizando o conjunto de peneiras de 0,59 e $0,30 \mathrm{~mm}$ de abertura, respectivamente. A fração retida na peneira de $0,59 \mathrm{~mm}$ foi submetida à nova moagem em moinho rotor marca Tecnal, modelo TE 651 (Brasil), com peneira de $0,84 \mathrm{~mm}$ de abertura, a fim de obter as frações farinha e farelo. A terceira fração, denominada integral, foi obtida pela moagem dos flocos de aveia em granulometria inferior a $0,59 \mathrm{~mm}$. As frações farinha, farelo e integral foram identificadas e armazenadas hermeticamente a $-20^{\circ} \mathrm{C}$ até o momento da realização das análises.

Os teores de umidade, proteína bruta, lipídios, carboidratos e fibra alimentar total foram determinados no aparelho marca Perstorp Analytical NIRSystems, modelo 5000 (Suécia), por meio de espectrofotometria do infravermelho proximal (NIRS) e os valores expressos em base seca. A matéria mineral foi determinada por calcinação a $600^{\circ} \mathrm{C}$, conforme método no $\mathrm{n}^{-942.05}$, e as $\beta$-glicanas, de acordo com o método no 995.116, ambas metodologias da AOAC (2012).

A atividade residual da enzima lipase foi determinada de acordo com o método proposto por KAUR et al. (1993), através do preparo de substrato pela homogeneização de $2 \mathrm{~g}$ de álcool polivinílico, $40 \mathrm{mg}$ de desoxicolato de sódio e $50 \mathrm{~mL}$ de óleo de oliva em $100 \mathrm{~mL}$ de tampão fosfato $0,2 \mathrm{~mol} \mathrm{~L}^{-1}, \mathrm{pH}$ 7,4 por 2,5 minutos. A seguir, $2 \mathrm{~g}$ de amostra foram dispersos em $5 \mathrm{~mL}$ de substrato, incubado a $38^{\circ} \mathrm{C}$ por 24 horas, sendo a reação paralisada pela adição de $20 \mathrm{~mL}$ de solução de álcool etílico e acetona (1:1), 
neutralizada. A atividade de lipase foi expressa em porcentagem de hidrólise com base no índice de saponificação do substrato.

A atividade residual da enzima peroxidase foi determinada de acordo com o método proposto por EKSTRAND et al. (1992) com adaptações. Uma massa de $0,625 \mathrm{~g}$ de amostra dissolvida em $25 \mathrm{~mL}$ de tampão TRIS-HCL 0,2 $\mathrm{mol} \mathrm{L}^{-1}, \mathrm{pH} 8,5$ foi agitada por 10 minutos e centrifugada por 15 minutos a 2000G. Uma alíquota de $0,5 \mathrm{~mL}$ do sobrenadante foi misturada com $3 \mathrm{~mL}$ da solução de substrato, realizando-se imediatamente a leitura da absorbância em espectrofotômetro Marca Unico, modelo 2100 (EUA), em comprimento de onda de $420 \mathrm{~nm}$, utilizando-se o substrato como branco para zerar o equipamento. O substrato foi preparado pela homogeneização de $1,55 \mathrm{~mL}$ de guaiacol, $50 \mathrm{~m} \mathrm{~mol}$ $\mathrm{L}^{-1}, 0,565 \mathrm{~mL}$ de peróxido de hidrogênio $20 \mathrm{~m} \mathrm{~mol} \mathrm{~L}^{-1}$ e $12,5 \mathrm{~mL}$ de etanol $5 \%$ em tampão acetato de sódio $0,1 \mathrm{~mol} \mathrm{~L}^{-1}, \mathrm{pH}$ de 5,0 qsp $250 \mathrm{~mL}$. Uma atividade de peroxidase corresponde ao aumento de 0,001 na absorbância a 420 $\mathrm{nm} \mathrm{min}^{-1} \mathrm{~g}^{-1}$ de amostra.

A quantificação dos compostos fenólicos solúveis totais (CFST) foi realizada em espectrofotômetro UV/Vis, marca Unico, modelo 2100 (EUA), de acordo com o método de FolinCiocalteau (SINGLETON et al., 1999), com leitura da absorbância em $764 \mathrm{~nm}$. Os resultados foram expressos em miligramas de equivalentes de ácido gálico (EAG) por 100 gramas de amostra seca.

$\mathrm{O}$ experimento foi conduzido em delineamento inteiramente casualizado, em arranjo fatorial $2 \times 3$ (processo $\mathrm{x}$ frações), totalizando seis tratamentos, realizados com duas repetições e as análises em triplicata. Os resultados foram submetidos à análise de variância (ANOVA) e nos modelos significativos as médias, comparadas entre si pelo teste de Tukey a 5\% de significância $(\mathrm{P} \leq 0,05)$.

\section{RESULTADOS E DISCUSSÃO}

Os valores de caracterização química, determinados em base seca nas frações farinha, farelo e integral de aveia, processadas hidrotermicamente em dois tempos de retenção, estão apresentados na tabela 1 . Os valores de cinzas não diferiram significativamente entre os tempos de retenção estudados, mas variaram estatisticamente entre as frações, sendo superiores no farelo. O teor de cinzas foi um importante indicativo de que os flocos foram adequadamente fracionados, pois a aveia possui maior concentração de minerais na parte externa do grão.

MÄLKKI \& VIRTANEN (2001) obtiveram valores de proteínas entre 12 e $18 \%$, para

Tabela 1 - Composição química (\%) das frações de aveia farinha, farelo e integral, processadas hidrotermicamente em escala industrial a $110^{\circ} \mathrm{C}$ e $49,05 \mathrm{kPa}$, nos tempos de retenção de 37 e 110 minutos.

\begin{tabular}{|c|c|c|c|c|}
\hline \multirow{2}{*}{ Parâmetro analisado } & \multirow{2}{*}{$\begin{array}{c}\text { Tratamento } \\
\text { Hidrotérmico (min) }\end{array}$} & \multirow[b]{2}{*}{ Farinha } & \multicolumn{2}{|c|}{---Frações------------------------------------------- } \\
\hline & & & Farelo & Integral \\
\hline \multirow{2}{*}{ Umidade (\%) } & 37 & $8,49 \pm 0,10^{\mathrm{Aa}}$ & $7,42 \pm 0,51^{\mathrm{Ba}}$ & $6,48 \pm 0,71^{\mathrm{Ca}}$ \\
\hline & 110 & $8,32 \pm 0,51$ Аa & $7,64 \pm 0,05^{\mathrm{Aa}}$ & $6,91 \pm 0,02 \mathrm{Ba}$ \\
\hline \multirow{2}{*}{ Cinzas (\%) } & 37 & $0,83 \pm 0,12^{\mathrm{Ca}}$ & $2,70 \pm 0,05^{\mathrm{Aa}}$ & $1,76 \pm 0,03^{\mathrm{Ba}}$ \\
\hline & 110 & $0,79 \pm 0,09^{\mathrm{Ca}}$ & $2,72 \pm 0,02^{\mathrm{Aa}}$ & $1,76 \pm 0,03^{\mathrm{Ba}}$ \\
\hline \multirow{2}{*}{ Proteínas (\%) } & 37 & $14,03 \pm 0,06^{\mathrm{Ca}}$ & $19,39 \pm 0,42^{\text {Аa }}$ & $16,57 \pm 0,20^{\mathrm{Ba}}$ \\
\hline & 110 & $14,05 \pm 0,10^{\mathrm{Ca}}$ & $18,60 \pm 0,15^{\mathrm{Ab}}$ & $15,64 \pm 0,09^{\mathrm{Bb}}$ \\
\hline \multirow{2}{*}{ Lipídios (\%) } & 37 & $6,87 \pm 0,06^{\mathrm{Ba}}$ & $8.49 \pm 0,70^{\mathrm{Aa}}$ & $8.26 \pm 0,65^{\mathrm{Aa}}$ \\
\hline & 110 & $7.49 \pm 0,06^{\mathrm{Aa}}$ & $7.51 \pm 0,10^{\mathrm{Ab}}$ & $7,90 \pm 0,11^{\mathrm{Aa}}$ \\
\hline \multirow{2}{*}{ Fibra alimentar (\%) } & 37 & $8,23 \pm 0,00^{\mathrm{Ca}}$ & $9,88 \pm 0,17^{\mathrm{Aa}}$ & $9,72 \pm 0,26^{\mathrm{Ba}}$ \\
\hline & 110 & $8,14 \pm 0,24^{\mathrm{Ca}}$ & $9,80 \pm 0,04$ Aa & $8,88 \pm 0,02^{\mathrm{Bb}}$ \\
\hline \multirow{2}{*}{ Carboidratos (\%) } & 37 & $73,60 \pm 0,50^{\mathrm{Aa}}$ & $65,50 \pm 1,05^{\mathrm{Ca}}$ & $69,70 \pm 0,81^{\mathrm{Bb}}$ \\
\hline & 110 & $73,10 \pm 0,13^{\text {Aa }}$ & $65,86 \pm 0,59^{\mathrm{Ca}}$ & $71,14 \pm 0,03^{\mathrm{Ba}}$ \\
\hline
\end{tabular}

Resultados expressos como média \pm desvio padrão; médias seguidas de mesmas letras minúsculas na coluna e maiúsculas na linha não diferem estatisticamente pelo teste de Tukey a $5 \%$ de probabilidade de erro. 
amostras de grãos de aveia, e entre 12 e $20 \%$, para amostras de farelo de aveia. Os valores de proteínas encontrados por SIMIONI et al. (2007) foram 14,45\% para cariopses de aveia branca analisados. Neste trabalho, os valores encontrados estão em acordo com os autores, sendo superiores no farelo. No tempo de retenção de $110 \mathrm{~min}$, foi observada redução no teor de proteínas das frações farelo e integral, sugerindo que a intensidade de tratamento térmico pode ter ocasionado reações tipo Maillard, imobilizando parte do nitrogênio pelas ligações com açúcares da aveia (ARAÚJO, 2011).

SÁ et al. (1998), estudando a variação da composição química de aveia tratada termicamente, encontraram valores de lipídios de $8,67 \%$. Os teores de lipídios são similares aos verificados no presente estudo, não diferindo significativamente entre os tempos de retenção estudados para as frações farinha e integral. No entanto, aos $110 \mathrm{~min}$ de retenção, o teor de lipídios da fração farelo foi significativamente inferior, sugerindo hidrólise lipídica. De acordo com LEHTINEN et al. (2003), a hidrólise de lipídios ocorre durante e imediatamente após o processamento se intensificando com o calor.

Os valores de fibra alimentar total não variaram significativamente entre os tempos de retenção estudados, porém foram estatisticamente diferentes entre as frações, com valores superiores no farelo. Em estudo realizado por SÁ et al. (2000), esse tipo de fibra atingiu $11,55 \%$ para a cultivar brasileira IAC 7.
Os resultados das determinações da atividade residual das enzimas lipase, peroxidase, teor de $\beta$-glicanas e de compostos fenólicos solúveis totais (CFST), determinados nas frações farinha, farelo e integral de aveia processadas hidrotermicamente em dois tempos de retenção, estão apresentados na tabela 2. A atividade residual da enzima lipase nas frações farinha e integral foi significativamente inferior no tempo de retenção de $110 \mathrm{~min}$, confirmando o emprego de maior intensidade de calor aplicado neste tratamento. WEBER et al. (2002), avaliando o efeito do tempo de imersão e da temperatura da água, observaram diminuição na atividade residual de lipase em aveia, sendo mais efetivo nos tratamentos com maiores tempo de imersão e temperatura. Resultados similares foram verificados por MARINI et al. (2007), quando o aumento da temperatura de secagem provocou diminuição da atividade residual de lipase. A lipase está presente tanto na fração farelo quanto no endosperma, em quantidades suficientes para causar a hidrólise lipídica nas frações (LEHTINEN et al., 2003) devendo reduzir sua atividade para fins de aumentar a vida de prateleira dos produtos de aveia

As frações farelo e integral, provenientes do tempo de retenção de $37 \mathrm{~min}$, apresentaram atividade residual de peroxidade superior, quando comparadas ao processo com 110min de duração, não sendo observada variação na fração farinha. Pelas condições de temperatura e pressão de vapor empregados neste estudo, pode-se afirmar que houve inativação parcial da atividade enzimática da

Tabela 2 - Atividade residual de lipase (\% hidrólise), peroxidase (Abs $420 \mathrm{~mm} \mathrm{~min}^{-1} \mathrm{~g}^{-1}$ ), teor de $\beta$-glicanas (\%) e de compostos fenólicos solúveis totais - CFST (mg EAG $100 \mathrm{~g}^{-1}$ amostra) das frações de aveia processadas em escala industrial a $110^{\circ} \mathrm{C}, 49,05 \mathrm{kPa}$, em 37 e 110 minutos.

\begin{tabular}{|c|c|c|c|c|}
\hline \multirow{2}{*}{ Parâmetro analisado } & \multirow{2}{*}{$\begin{array}{c}\text { Tratamento } \\
\text { Hidrotérmico (min) }\end{array}$} & \multicolumn{3}{|c|}{ 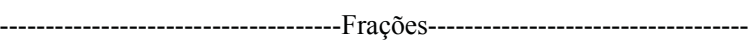 } \\
\hline & & Farinha & Farelo & Integral \\
\hline \multirow{2}{*}{ Lipase residual (\% hidrólise) } & 37 & $4,45 \pm 0,29^{\mathrm{Ca}}$ & $10,64 \pm 0,16^{\mathrm{Aa}}$ & $8,16 \pm 0,49^{\mathrm{Ba}}$ \\
\hline & 110 & $2,35 \pm 0,19^{\mathrm{Cb}}$ & $10,09 \pm 0,96^{\mathrm{Aa}}$ & $6,47 \pm 0,48^{\mathrm{Bb}}$ \\
\hline \multirow{2}{*}{ Peroxidase residual $\left(\mathrm{Abs}_{420 \mathrm{~mm}} \min ^{-1} \mathrm{~g}^{-1}\right)$} & 37 & $4160 \pm 484,42 \mathrm{Ca}$ & $13060 \pm 11,56^{\mathrm{Aa}}$ & $6800 \pm 7,30^{\mathrm{Ba}}$ \\
\hline & 110 & $4140 \pm 596,43^{\mathrm{Ca}}$ & $10060 \pm 7,79^{\mathrm{Ab}}$ & $6090 \pm 3,58^{\mathrm{Bb}}$ \\
\hline \multirow{2}{*}{$\beta$-glicanas $(\%)$} & 37 & $1,66 \pm 0,14^{\mathrm{Ca}}$ & $6,56 \pm 0,11^{\text {Aa }}$ & $3,86 \pm 0,36^{\mathrm{Ba}}$ \\
\hline & 110 & $1,50 \pm 0,12^{\mathrm{Ca}}$ & $6,24 \pm 0,02{ }^{\text {Аa }}$ & $3,12 \pm 1,11^{\mathrm{Ba}}$ \\
\hline \multirow{2}{*}{$\mathrm{CFST}^{1}\left(\mathrm{mg}\right.$ EAG $\left.100 \mathrm{~g}^{-1}\right)$} & 37 & $394,75 \pm 3,82^{\mathrm{Ca}}$ & $717,50 \pm 10,15^{\mathrm{Aa}}$ & $662,00 \pm 7,38^{\mathrm{Ba}}$ \\
\hline & 110 & $279.00 \pm 21,86^{\mathrm{Cb}}$ & $493,00 \pm 2,93^{\mathrm{Ab}}$ & $437,00 \pm 2,68^{\mathrm{Bb}}$ \\
\hline
\end{tabular}

${ }^{1}$ compostos fenólicos solúveis totais, expressos como $\mathrm{mg}$ de equivalente ácido gálico -EAG- por 100g de amostra. Resultados expressos como média \pm desvio padrão; médias seguidas de mesmas letras minúsculas na coluna e maiúsculas na linha não diferem estatisticamente pelo teste de Tukey a 5\% de probabilidade de erro. 
peroxidase. Estes resultados estão em acordo com os obtidos por MARINI et al. (2007), que observaram decréscimo na atividade desta enzima com realização de secagem estacionária de aveia em temperatura do ar superior a $80^{\circ} \mathrm{C}$. A peroxidase é usada como indicadora da intensidade de tratamento em produtos de aveia processados termicamente.

Os teores de $\beta$-glicanas das frações farinha, farelo e integral não variaram significativamente com o tempo de retenção na coluna, sendo superiores no farelo, seguido de integral e farinha. Isso indica que a intensidade do tratamento hidrotérmico industrial não promoveu redução do teor de $\beta$-glicanas nas frações estudadas. SÁ et al. (2000), trabalhando com genótipos brasileiros, observaram valores de $\beta$-glicanas entre 3,51 e $6,50 \%$, similares aos valores encontrados neste estudo. Por outro lado, OLIVEIRA et al. (2010), estudando o efeito de diferentes temperaturas do ar de secagem na qualidade de grãos de aveia, verificaram que, acima de $75^{\circ} \mathrm{C}$, ocorreu redução no teor de $\beta$-glicanas.

A concentração de compostos fenólicos encontrada neste estudo diferiu significativamente entre os tempos de retenção em todas as frações estudadas, sendo superior no tratamento mais brando (37min). Os compostos fenólicos foram parcialmente solubilizados pelo vapor d'água em função da intensidade do tratamento hidrotérmico aplicado na aveia.

A concentração de fenólicos totais encontrada nas frações de aveia provenientes dos processos analisados foi relativamente elevada, quando comparada ao estudo realizado por IQBAL et al. (2007), que encontraram, para a fração de farelo de trigo, valores de compostos fenólicos de $268 \mathrm{mg}$ EAG $100 \mathrm{~g}^{-1}$. SERPEN et al. (2008), estudando o conteúdo de compostos fenólicos solúveis totais em diversos cereais, encontraram valores de $285 \mathrm{mg}$ EAG $100 \mathrm{~g}^{-1}$ para grãos de aveia descascados e moídos, sendo inferior ao encontrado no presente estudo para a fração integral.

A fração farelo concentrou o maior percentual de compostos fenólicos em relação às frações farinha e integral de aveia. Esses resultados estão em acordo com PETERSON (2001), ao afirmar que os compostos fenólicos na aveia estão associados principalmente ao pericarpo. A concentração de compostos fenólicos totais, encontrada na fração farelo, foi de $717 \mathrm{mg}$ EAG $100 \mathrm{~g}^{-1}$ aos $37 \mathrm{~min}$ de processo. Essa fração, rica em fibras, apresentou concentração de fenólicos $80 \%$ superior, quando comparada à fração farinha, rica em amido. Por outro lado, a intensidade do tratamento hidrotérmico a 110 min degradou em cerca de $50 \%$ a concentração desses compostos nas frações analisadas. Os resultados deste estudo confirmam que as frações de aveia ricas em fibras contêm maior concentração de compostos fenólicos, quando comparadas às ricas em amido, devendo ser processadas em condições brandas para preservar estes compostos.

\section{CONCLUSÃO}

Os constituintes químicos das frações farinha, farelo e integral foram pouco afetados nos tempos de retenção estudados. O tempo de retenção na coluna do tratador hidrotérmico de $37 \mathrm{~min}$ se mostra mais adequado por ser suficiente para inativar as enzimas lipase e peroxidase, indicadoras da intensidade de tratamento térmico, além de preservar os compostos fenólicos solúveis totais em todas as frações de aveia estudadas. As frações de aveia ricas em fibras contêm maior concentração de compostos fenólicos, quando comparadas às ricas em amido.

\section{AGRADECIMENTOS}

Os autores agradecem ao Conselho Nacional de Desenvolvimento Científico Tecnológico (CNPq) pelo auxílio financeiro, processo 471741/2010-8. À Indústria Saboreal Cereais e Alimentos Ltda., Ajuricaba, RS, pela produção e fornecimento das amostras.

\section{REFERÊNCIAS}

ARAÚJO, J.M.A. Escurecimento não enzimático. In: Química de alimentos: teoria e prática. 5.ed. Viçosa: UFV, 2011. Cap.15, p.437-458. ISBN: 978-85-7269-404-9.

AOAC (ASSOCIATION OF OFFICIAL ANALYTICAL CHEMISTS). Official methods of analysis of the Association of Official Analytical Chemists. 19.ed. Arlington: AOAC International, 2012. $2 \mathrm{v}$

BUTT, M.S. et al. Oat: unique among the cereals. European Journal of Nutririon, v.47, n.2, p.68-79, 2008. Disponível em: $<$ http://www.ncbi.nlm.nih.gov/pubmed/18301937>. Acesso em: 8 maio, 2013. doi: 10.1007/s00394-008-0698-7.

CRESTANI, M. et al. Conteúdo de $\beta$-glucana em cultivares de aveia-branca cultivadas em diferentes ambientes. Pesquisa Agropecuária Brasileira, v.45, n.3, p.261-268, 2010. Disponível em: <http://dx.doi.org/10.1590/S0100204X2010000300005>. Acesso em: 8 maio, 2013. doi: 10.1590/ S0100-204X2010000300005.

EKSTRAND, B. et al. Lipase activity in oats - distribution, $\mathrm{pH}$ dependence and heat inactivation. Cereal Chemistry, v.69, n.4, p.379-381, 1992. Disponível em: <http://www.aaccnet. org/publications/cc/backissues/1992/Documents/69_379.pdf $>$. Acesso em: 8 maio, 2013.

LEHTINEN, P. et al. Effect of heat treatment on lipid stability in processed oats. Journal of Cereal Science, v.37, n.2, p.215-221, 
2003. Disponível em: $<$ http://www.sciencedirect.com>. Acesso em: 12 ago. 2013. doi: 10.1006/jers.2002.0496.

IQBAL, S. et al. Antioxidant properties and components of bran extracts from selected wheat varieties commercially available in Pakistan. LWT - Food Science and Technology, v.40, p.361-367, 2007. Disponível em: <http://dx.doi.org/10.1016/j.lwt.2005.10.001>. Acesso em: 8 maio, 2013. doi: 10.1016/j.lwt.2005.10.001.

KAUR, J. et al. Characterization of oat lipase for lipolysis of rice bran oil. Biotechnology Letters, v.15, n.3, p.257262, 1993. Disponível em: <http://link.springer.com/ article/10.1007\%2FBF00128315>. Acesso em: 8 maio, 2013. doi: $10.1007 / \mathrm{BF} 00128315$.

MÄLKKI, Y.; VIRTANEN, E. Gastrointestinal effects of oat bran and oat gum - A rewiew. LWT - Food Science and Technology, v.34, p.337-347, 2001. Disponível em: <http://dx.doi.org/10.1006/ fstl.2001.0795>. Acesso em: 8 maio, 2013. doi: fstl.2001.0795.

MARINI, L.J. et al. Efeito da secagem intermitente na estabilidade de grãos de aveia. Brazilian Journal of Food Technolology, v.8, n.3, p.260-267, 2005. Disponível em: <http://bj.ital.sp.gov.br/ artigos/html/busca/PDF/v8n3213p.pdf > . Acesso em: 8 maio, 2013. ISSN 1517-7645.

MARINI, L.J. et al. Efeito da temperatura de secagem e relação de intermitência na inativação enzimática e viscosidade de pasta de aveia. Revista Brasileira de Agrociência, v.13, n.1, p.55-60, 2007. Disponível em: $<$ http://periodicos.ufpel.edu.br/ojs2/index. php/CAST/article/view/1338/1122>. Acesso em: 8 maio, 2013.

OLIVEIRA, L.C. et al. Efeito da temperatura de secagem na qualidade de grãos de aveia branca. Ciência e Agrotecnologia, v.34, n.2, p.313-319, 2010. Disponível em: <http://dx.doi org/10.1590/S1413-70542010000200007>. Acesso em: 8 maio, 2013. doi: 10.1590/S1413-70542010000200007.

PETERSON, D.M. Oat antioxidants. Journal of Cereal Science, v.33, n.2, p.115-129, 2001. Disponível em: <http://dx.doi. org/10.1006/jcrs.2000.0349>. Acesso em: 8 maio, 2013. doi: $10.1006 /$ jcrs. 2000.0349

SÁ, R.M. et al. Composição química do cultivar de aveia (Avena sativa L.) IAC 7 e influência do processamento térmico sobre suas características. Brazilian Journal of Food Technology, v.1, n.1, p.53-58, 1998. Disponível em: <http://bj.ital.sp.gov.br/artigos/ html/busca/PDF/v01nu06a.pdf>. Acesso em: 8 maio, 2013.

SÁ, R.M. et al. Variação no conteúdo de $\beta$-glicanas em cultivares brasileiros de aveia. Ciência e Tecnologia de Alimentos, v.20, n.1, p.99-102, 2000. Disponível em: <http://dx.doi.org/10.1590/ S0101-20612000000100019>. Acesso em: 8 maio, 2013. doi: 10.1590/S0101-20612000000100019.

SERPEN, A. et al. Direct measurement of the total antioxidant capacity of cereal products. Journal of Cereal Science, v.48, p.816-820, 2008. Disponível em: <http://dx.doi.org/10.1016/j. jcs.2008.06.002>. Acesso em: 8 maio, 2013. doi: 10.1016/j. jes.2008.06.002.

SIMIONI, D. et al. Caracterização química de cariopses de aveia branca. Alimentos e Nutrição, v.18, n.2, p.191-196, 2007.

SINGLETON, V.L. et al. Analysis of total phenols and other oxidation substrates and antioxidants by means of Folin-Ciocalteau reagent. Methods in Enzymology, v.299, n.1, p.152-178, 1999. Disponível em: <http://dx.doi.org/10.1016/S0076-6879(99)990171>. Acesso em: 8 maio, 2013. doi: 10.1016/S0076-6879(99)99017-1.

WEBER, F.H. et al. Processo de estabilização de farinha de aveia por imersão das cariopses em água quente. Brazilian Journal of Food Technology, v.5, p.225-235, 2002. Disponível em: <http:// bj.ital.sp.gov.br/artigos/brazilianjournal/free/c02103.pdf>. Acesso em: 8 maio, 2013

WOOD, P.J. Cereal $\beta$-glucans in diet and health. Journal of Cereal Science, v.46, p.230-238, 2007. Disponivel em: $<\mathrm{http} / /$ dx.doi.org/10.1016/j.jcs.2007.06.012>. Acesso em: 8 maio, 2013. doi: $10.1016 /$ j.jcs.2007.06.012 